\title{
COVID-proofing Biochemistry and engaging diverse students with Crystallography Research \\ Oluwatoyin Asojo
}

\author{
Hampton University Department of Chemistry and Biochemistry, ${ }^{2} 200$ William R. Harvey Way Hampton VA 23668
}

Oluwatoyin.asojo@hamptonu.edu

My objective is to share approaches by which I incorporate structural biology into our biochemistry curriculum at Hampton University. I will also discuss methods to engage K-12 and undergraduate students in crystallographic research and structural biology (since 2001). I will show the successes and failures involved in the process of fully integrating these pre-baccalaureate students in crystallography research. Our outreach efforts have included socioeconomically underserved students or groups underrepresented in STEM. We will present strategies for recruiting and retaining STEM students. We will present the significant barriers to our research programs. We will also discuss potential funding sources. Finally, we will present how structural science has helped COVID-proof our research and biochemistry teaching approach over the past year of remote-learning.

Keywords: Education, virtual learning, STEM, Diversity, engagement 